\title{
Efficient dye adsorption by highly porous nanofiber aerogels
}

\author{
Sara Mousavi ${ }^{1,2}$, Fabian Deuber ${ }^{1}$, Sergio Petrozzi ${ }^{1}$, Lukas Federer ${ }^{1}$, Majid Aliabadi ${ }^{3}$, Farhad \\ Shahraki ${ }^{2}$, Christian Adlhart ${ }^{1^{*}}$ \\ ${ }^{I}$ Institute of Chemistry and Biotechnology, Zurich University of Applied Sciences ZHAW, 8820 Wädenswil, Switzerland \\ ${ }^{2}$ Department of Chemical Engineering, University of Sistan and Baluchestan, Zahedan, Iran \\ ${ }^{3}$ Department of Chemical Engineering, Birjand Branch, I.A.U. University, Birjand, Iran
}

\begin{abstract}
Electrospun nanofiber membranes are frequently used in adsorption processes thanks to their high specific surface area, tailored surface functionality, and fiber uniformity. However, they are still facing challenges such as low mechanical stability and unfavorable mass transport properties. In this study, an ultra-light and robust 3D nanofiber aerogel (NFA) or nanofiber sponge with tunable porosity and flexibility was synthesized from short pullulan/polyvinyl alcohol/polyacrylic acid nanofibers using a freeze casting process followed by thermal crosslinking. We demonstrate time the application of such NFAs in batch and continuous adsorption systems and compare their performance with flat nanofiber membranes (NFM). The NFAs proved to be promising adsorbents for cationic dyes due to their high adsorption capacity $(383 \mathrm{mg} / \mathrm{g})$ and their reusability. Langmuir isotherm was a suitable model for describing the adsorption process. The endothermic system followed a pseudo second order kinetic model and intra-fiber adsorption is found to be involved in the adsorption process. Dye adsorption by 3D NFAs was four times faster than for the respective flat NFMs and when used in a continuous process as a deep-bed filter, the pressure drop through the NFA was reduced by a factor of 40 while maintaining equal adsorption performance as for the NFM.
\end{abstract}




\section{Keywords}

water purification; nanofiber sponge; adsorption; mass transport; electrospinning 


\section{Graphical Abstract Art}

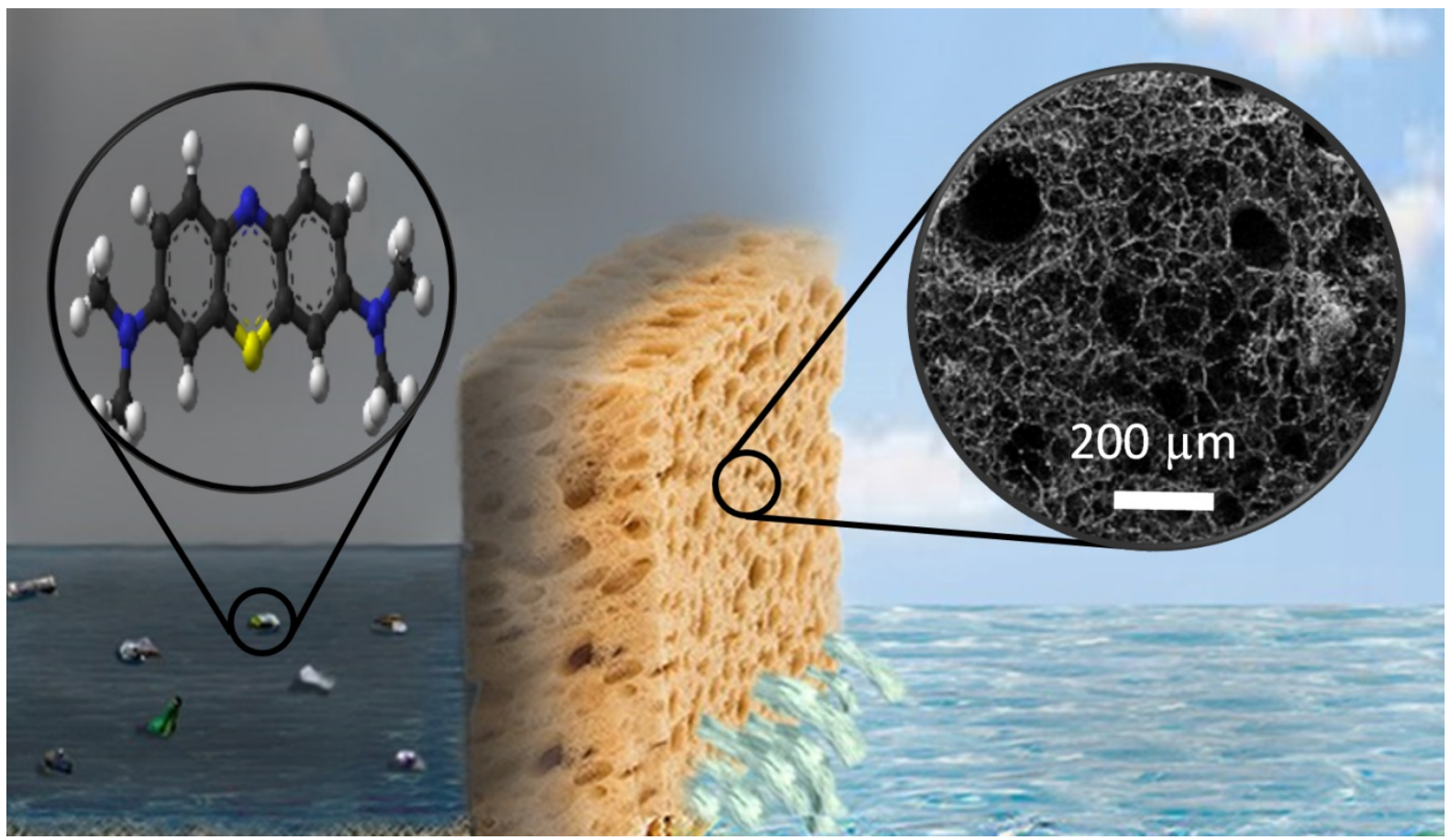

\section{Highlights}

- Nanofiber aerogels (NFAs) were synthesized from electrospun nanofibers

- Adsorption capacity of the electrospun nanofiber membrane (NFM) was retained

- The open porous structure of the NFA significantly facilitates mass transport of fluids

- Pressure drop within the NFA is reduced by a factor of 40 compared to the NFM 


\section{Introduction}

Dyeing processes are an integral part of huge industries including paper, textile and paint, resulting in high amounts of water soluble dyes in wastewaters. This introduces environmental challenges due to the negative effects of dyes on aqueous ecosystems by their intrinsic toxicity and their sunlight inhibiting properties. Therefore, removal of dyes from wastewater is an important subject all over the world [1-5].

Adsorption is one of the most promising and environmentally friendly separation methods for removing dyes. Adsorption is free of toxic by-product, cost efficient, flexible and technically simple [6]. Previous research on different effective adsorbents such as activated carbon[7, 8], agricultural solid wastes [9-11], industrial by-products [6, 12], and inorganic materials [13] prove the outstanding effect of high surface area per volume on the adsorption process; therefore powdery adsorbents are a good choice for dye adsorption. Regarding secondary challenges including powder removal after finishing the process for regeneration or disposal, electrospun nanofiber membranes are an effective alternative [14-20].

Recently, nanofiber aerogels (NFAs) or nanofiber sponges were introduced as a new class of ultra-light highly porous materials [21]. In contrast to classical aerogels which are obtained through a sol-gel process, preformed nanofibers are used as their building blocks [22]. Porosity and pore architecture of nanofiber aerogels can be fine-tuned during the integral cryogenic solidification step $[23,24]$. This allows combining the filtration challenges of high surface area per volume and efficient adsorbent removal. Moreover, the broad range of materials and surface chemistry available for nanofibers can be exploited for NFAs as well [25-27]. Nanofiber aerogels have also promising mechanical properties as compared to hydrogels employed for water purification [28]. 
Tuning the microstructure of NFAs is also essential for the macroscopic mass transport properties during dye adsorption: this was also shown for classical aerogels, where controllable porosity was achieved through a freeze-casting-based process [29, 30], allowing for instance the construction of the most effective natural hydrogel for removal of $\mathrm{Cr}(\mathrm{VI})$ [31].

Despite promising achievements of the previous studies, there has been no attempt on developing biocompatible spongy aerogel structures from nanofibers suitable for dye removal. Recently, a three-dimensional nanofiber aerogel was introduced by our research group using pullulan as a natural, edible, tasteless and water soluble polysaccharide [24, 32]. The objective of this study was to assess the efficiency of pullulan-based NFAs in the adsorption of methylene blue (MB) as a cationic dye operated in batch and continuous processes. Adsorption capacity, dynamic properties, and reusability of the NFA were investigated and their performance was compared with the respective nanofiber membranes (NFMs).

\section{Materials and Methods}

Chemicals. 1,4-Dioxane (ACS reagent, $>99 \%$ ), PVA (polyvinyl alcohol) $(\mathrm{Mw}=89000$ $98000 \mathrm{Da}, \mathrm{DH}=99 \%)$, PAA (polyacrylic acid sodium salt) $(\mathrm{Mw}=5100), \mathrm{NaOH}($ sodium hydroxide), $\mathrm{HCl}$ (hydrochloride acid, ACS reagent, $37 \%$ ) were all purchased from Sigma Aldrich, Germany. Methylene blue (MB) was obtained from Honeywell Riedel de Haën, USA and pullulan (food grade) was provided by Hayashibara Co. Ltd, Japan.

Nanofiber aerogel preparation. 3-D nanofiber aerogels were prepared following the process introduced in our previous work [24]. Briefly, according to Fig. 1, nanofibers were obtained by electrospinning an aqueous polymer solution with $14.5 \%$ mass fraction of pullulan/PVA/PAA (ratio 3:2:2). Then, they were dispersion cut into short fragments in 1,4dioxane (10 $\mathrm{mg} \mathrm{ml}^{-1}$ ) using a high speed homogenizer (IKA T25, S25N-25F, IKA GmbH). 
The dispersion was then unidirectionally frozen and crystals of dioxane grow from the bottom of container to the top. The short nanofibers were entrapped between the growing crystals. In the next step, the solidified solvent was removed by sublimation and the green body of the porous nanofiber aerogel was obtained. Thermal crosslinking rendered the stable and water insoluble 3D nanofiber aerogel used for the dye removing processes. By controlling the crosslinking temperature and time, we were able to obtain water insoluble nanofiber aerogels without the necessity of adding any new chemicals. For detailed information see our previous work [24].

Filtration and regeneration procedures. Batch experiments were carried out by stirring dye solutions with known initial concentration using defined amounts of nanofiber aerogel as adsorbent. The cationic dye MB was used as a water soluble model substance due to different applications of this dye in chemistry and biology [33]. Continuous adsorption properties of nanofiber aerogels were investigated by pumping dyed solutions through columns containing fitted with a piece of nanofiber aerogel as the adsorbent. Regeneration of the adsorbent was possible by washing the nanofiber aerogels at acidic conditions of $\mathrm{pH} 3$. In order to compare the operability and efficiency of 3D NFAs with flat NFMs, batch and continuous experiments were done for NFM at the same conditions. The detailed information regarding filtration parameters and conditions is provided in the supporting information.

\section{Results and discussion}

Morphology and structure of the NFA. The synthesized NFA was a 3D body with a density of only $24.5 \pm 2.3 \mathrm{mg} \mathrm{l}^{-1}$. Fig. $2 \mathrm{~A}$ shows a piece of the aerogel on the top of a dandelion illustrating its light character. The porosity $\varphi$ of the NFA was $98.2 \pm 0.2 \%$ based on Equation $1[24]$.

$$
\varphi=\frac{V_{\mathrm{p}}}{V} \cdot 100 \%=\frac{\left(V-\frac{m}{\rho}\right)}{V} \cdot 100 \%
$$


Where $\varphi$ is the porosity, $V$ is the total bulk volume of the aerogel, $V_{\mathrm{p}}$ is the pore volume, $m$ is the mass and $\rho$ is the density of the polymeric material.

The hierarchical pore architecture of the NFA is illustrated in SEM images of cross sections of the material, Fig $2 \mathrm{~B}$ and $2 \mathrm{C}$. The larger cellular pores have a diameter between $20-40 \mu \mathrm{m}$ (Supporting information), which is in contrast to the flat NFM with small pores between 2-5 $\mu \mathrm{m}$. The open porous structure of the NFA allows rapid water uptake and they show a high liquid holding capacity [24].

The nanofiber aerogel becomes stable and water insoluble after thermal crosslinking, where ether bonds are formed as confirmed by FT-IR as well as contact angle measurements (Fig S5). The degree of crosslinking and thus hydrophobicity can be tuned by adapting the thermal crossliniking conditions according to our previous work [24].

Batch dye adsorption. To investigate the adsorption properties of the nanofiber aerogel, different parameters such as $\mathrm{pH}$, concentration, temperature and amount of adsorbent were assessed.

The equilibrium adsorption capacity $Q_{\mathrm{e}}$ can be determined from Equation 2 [6].

$$
Q_{\mathrm{e}}=\frac{\left(\gamma_{0}-\gamma_{\mathrm{e}}\right) V}{m}
$$

Where $\gamma_{0}$ and $\gamma_{\mathrm{e}}$ are the initial and equilibrium mass concentrations of the dye, $V$ is volume of solution and $m$ is the mass of nanofiber aerogel adsorbent.

The adsorption efficiency $\phi$ of MB was calculated according to 3.

$$
\phi=\frac{\gamma_{0}-\gamma_{\mathrm{e}}}{\gamma_{0}} \times 100 \%
$$

Effects of initial dye concentration. Fig. 3A shows the effect of dye concentration on the adsorption capacity of the NFA. Increasing amount of adsorbed dye per unit mass of NFA with increasing dye concentration in the solution was observed. 
Increasing equilibrium adsorption capacity for higher concentrated solutions indicates the presence of free adsorption sites within the aerogel. So the "less accessible sites" are available at higher concentration [6].

Effect of adsorbent dose. The effect of NFA amount in adsorption is presented in Fig. 3B. The removal efficiency is increasing from $18.7 \%$ to $99 \%$ with increasing the adsorbent amount from 30 to $300 \mathrm{mg}$. On the other hand, the time required for reaching the equilibrium decreases with higher dose of aerogel. This is caused by increasing mass transport due to the raise in aerogel surface. This graph shows that dye adsorption can be a very fast process. For instance, when $200 \mathrm{mg}$ of aerogel are used, around $55 \%$ of dye is removed during 2.5 minutes of adsorption.

Effect of $\mathbf{p H}$. According to Fig. 3C, increased $\mathrm{pH}$ provides a suitable environment for the adsorption process while adsorption efficiency at acidic conditions is very low.

$\mathrm{MB}$ is normally a cationic dye with the form of $\mathrm{MB}^{+}$. On the other hand, basic environment increases the amount of deprotonated hydroxy functional groups located at the surface of the pullulan/PVA/PAA nanofibers. This is necessary for complex formation through an electrostatic interaction between $\mathrm{MB}^{+}$and $\mathrm{O}^{-}$. However, in acidic conditions deprotonated hydroxy groups are no longer available. Therefore, the adsorption capacity dramatically decreases.

Effect of temperature. Fig. 3D clearly indicates the positive effect of higher temperature on adsorption velocity.

From the temperature effects, the thermodynamic constants standard adsorption enthalpy $\left(\Delta H^{0}\right)$, standard adsorption entropy $\left(\Delta S^{0}\right)$ and standard Gibbs energy of adsorption $\left(\Delta G^{0}\right)$ are calculated using Equations 4 and 5 [34].

$$
\ln K_{\mathrm{d}}=\frac{\Delta S^{0}}{R}-\frac{\Delta H^{0}}{R T}
$$




$$
\Delta G^{0}=\Delta H^{0}-T \Delta S^{0}
$$

Where $R$ is the molar gas constant, $T$ is the absolute temperature in Kelvin and $K_{\mathrm{d}}$ is the distribution coefficient of dye $\left(\mathrm{g} \mathrm{g}^{-1}\right)$ which follows from Equation 6:

$$
K_{\mathrm{d}}=\frac{Q_{\mathrm{e}}}{\gamma_{\mathrm{e}}}
$$

The calculated thermodynamic parameters are reported in Table 1 . The positive value of $\Delta H^{0}$ shows that the dye adsorption process is endothermic and that adsorption is driven by the positive adsorption entropy. Therefore, the degree of adsorption increases with higher temperature as can be observed in Fig. 3D as well.

Effects of ionic strength, ionic radius and charges on adsorption. Since presence of salts in wastewaters containing dyes is inevitable, investigating effects of ions in all the treatment strategies is crucial.

Different concentration of $\mathrm{NaCl}$ solutions (from 0.0 to $0.2 \mathrm{M}$ ) were used for showing the effects of ion strength on adsorption since $\mathrm{NaCl}$ is often used as stimulator in dyeing processes [35]. Fig. 4A demonstrates that increasing the amount of ions has a negative effect on the adsorption efficiency, especially when the ion concentration is higher than $0.05 \mathrm{M}$.

It is clear that adding salts affects adsorption by screening (damping) the electrostatic force between the MB molecules and the pullulan/PVA/AA aerogel which significantly decreases the adsorption efficiency [36].

Since the presence of ions is a very critical parameter, the effect of ionic radius and different charges was investigated using $\mathrm{Li}^{+}, \mathrm{Na}^{+}$, and $\mathrm{K}^{+}$as model ions with same charges and different radii and $\mathrm{Mg}^{2+}$ with higher charge. According to Fig. 4b, larger radii increase the screening effect, while decrease the adsorption capacity. However, comparison between $\mathrm{Na}^{+}$and $\mathrm{Mg}^{2+}$ indicates that not only the radius but also the charge of ions has a very significant effect on the adsorption process. However, according to previous reports [37], the 
favourable complex formation between $\mathrm{Mg}^{2+}$ and hydroxyl groups in the nanofiber aerogel due to a chelating effect is anticipated to compete with MB for free adsorption.

Effects of different externally induced strains. As mentioned before, the pullulan/PVA/PAA aerogel has a highly porous structure with interconnected pores. Therefore, effects of induced pressure on the aerogel or stirring in comparison with no external forces during the adsorption process were investigated as presented in Fig. 5A-C. Inducing compression and release cycles on the NFA increases the velocity of dye adsorption due to the enforced mass transport of the dye solution through the pores of the NFA (Fig. 5A). Stirring the dye solution increases adsorption velocity (Fig. 5B) compared to the situation without any external force. Then dye adsorption becomes slow and the adsorption equilibrium will settle only after 24 hours (Fig. 5C) representing diffusion without any external force.

The batch adsorption experiments clearly demonstrate the favourable architecture of NFAs for dye adsorption: (I) the large specific surface area due to the application of nanofibers and (II) the open porous architecture of the aerogel enabling favourable mass transport of the dye solution to the surface of the nanofibers.

Continuous adsorption system. Although the batch system investigation is essential for each adsorption process to understand and describe intrinsic characteristics of the adsorbent, continuous flow systems are much more useful for the industrial scale where large volumes of wastewater are generated.

Therefore, NFAs were packed as a depth filter into a column and the dye solution was pumped at constant rate through the NFA. As illustrated in Fig 6A, $100 \mathrm{~mm}$ of aerogel $(0.78$ $\left.\mathrm{cm}^{3}\right)$ in a continuous flow $\left(4.5 \mathrm{ml} \mathrm{min}^{-1}\right)$ of $10 \mathrm{ppm}$ concentrated solution retained the dye for almost $40 \mathrm{~min}$. At this breakthrough point, dye found the first path through the aerogel. A second path was observed at around $100 \mathrm{~min}$ and the mass concentration of dye in the filtrate 
was increasing until the aerogel was completely saturated with the dye. The inserts show photographs of NFAs that had been removed at representative stages of such continuous adsorption experiments. Fig $6 \mathrm{~B}$ is representing a comparison between the performance and breakthrough point of $8 \mathrm{mg}$ of stacked NFM sheets and the same amount of NFA (40 mm) in continuous experiments. It is obvious that the flat NFMs are reaching the breakthrough point later than the NFA. However, the very high pressure difference between them ( 5.5 bar instead of 0.14 bar for the NFM and the NFA, respectively) leaves the applicability of NFMs very limited and introduces the NFA as a suitable adsorbent for continuous processes. Comparing Fig $6 \mathrm{~A}$ and $6 \mathrm{~B}$ can also indicates that adsorption of $\mathrm{MB}$ is highly dependent on the bed depth, which represents the quantity of adsorbent in the column. Increasing the bed depth enhances the breakthrough time: E.g. The breakthrough point changes from $30 \mathrm{sec}$ to $40 \mathrm{~min}$ for 40 $\mathrm{mm}(8 \mathrm{mg})$ and $100 \mathrm{~mm}(30 \mathrm{mg})$ aerogel length respectively. These experiments demonstrate the potential of NFAs in continuous water purification processes due to their highly porous architecture and large internal surface with hydroxy functional groups.

Equilibrium isotherm models. Optimization of dye adsorption process is possible when the adsorption isotherms are known. Equilibrium isotherms can describe adsorption mechanisms as well as surface properties to make a reliable prediction of how pollutants interact with the NFA. Among several different isotherm models, Langmuir and Freundlich are commonly used for describing experimental dye adsorption data $[6,38,39]$.

Langmuir isotherm. The Langmuir isotherm is one of the most successfully applied isotherms in many different adsorption processes. The model is based on three assumptions of first a homogeneous surface, second a localized adsorption, and third that each active site can accommodate only one molecule. The linearized Langmuir equation is presented as Equation 7:

$$
\frac{1}{Q_{\mathrm{e}}}=\frac{1}{Q_{\max }}+\frac{1}{K_{\mathrm{L}} Q_{\max }} \times \frac{1}{\gamma_{\mathrm{e}}}
$$


Where $Q_{\mathrm{e}}$ is the dye equilibrium adsorption capacity ( $\left.\mathrm{mg} \mathrm{g}_{\text {aerogel }}^{-1}\right), Q_{\max }$ is the maximum dye adsorption capacity ( $\left.\mathrm{mg} \mathrm{g}_{\text {aerogel }}^{-1}\right), \gamma_{\mathrm{e}}$ is the equilibrium mass concentrations of the dye in the liquid phase $\left(\mathrm{mg} \mathrm{l}^{-1}\right)$, and $K_{\mathrm{L}}$ is the Langmuir constant $\left(\mathrm{l} \mathrm{mg}^{-1}\right)$.

However, the essential factor in Langmuir isotherm is expressed by the dimensionless separation factor or equilibrium parameter $\left(R_{\mathrm{L}}\right)$ which is defined as follows [40]:

$$
R_{\mathrm{L}}=\frac{1}{1+K_{\mathrm{L}} \gamma_{0}}
$$

Where $\gamma_{0}$ is the initial mass concentration of the dye $\left(\mathrm{mg} \mathrm{l}^{-1}\right)$. This value differentiates between irreversible $\left(R_{L}=0\right)$, favorable $\left(0<R_{L}<1\right)$, linear $\left(R_{L}=1\right)$, or unfavorable $\left(R_{L}>1\right)$ adsorption processes [6].

Freundlich isotherm. The empirical Freundlich equation is more suitable for non-ideal processes with rough and heterogeneous surfaces where the energy term changes as a function of surface coverage (Equation 9).

$$
\lg Q_{\mathrm{e}}=\frac{\lg \gamma_{\mathrm{e}}}{n}+\lg K_{\mathrm{F}}
$$

Where $K_{\mathrm{F}}$ is the Freundlich constant representing the dye adsorption capacity $\left(\mathrm{lg}_{\text {aerogel }}^{-1}\right)$ and $n$ is an empirical parameter representing the heterogeneity of the adsorption sites [41].

Table 2 summarized the parameters and constants of the investigated isotherms. The relevant fitted curves are also displayed in Fig S6. According to calculated $R^{2}$ values, the adsorption process obeys the Langmuir monolayer isotherm having the better fit than the Freundlich model. Based on electrostatic attractions, surface hydroxy groups of the NFA are occupied by cationic dye and no more adsorption is possible on those sites. Forming a monolayer of dye during batch experiments on the surface of adsorbent was proved by some other studies [42]. Moreover, the calculated maximum capacity of the NFA using Langmuir model was 370.37 $\mathrm{mg} \mathrm{g}^{-1}$ which is close to the experimental results $\left(383.43 \mathrm{mg} \mathrm{g}^{-1}\right)$, confirming that the 
Langmuir isotherm is suitable to explain the adsorption process. Furthermore, the calculated $R_{\mathrm{L}}=0.0018$, which is between 0 and 1 , shows a favourable adsorption process between the NFA and MB (Table 2).

Adsorption kinetics. Some essential information about sorption procedure and the solute uptake rate is provided by studying the adsorption kinetics. Since it is essential for evaluating the effectiveness of adsorbent, kinetics are used for designing a proper adsorption system. To investigate the mechanisms of adsorption, different kinetic models such as pseudo first and second order or intra particle diffusion have been reported:

Pseudo first order or Lagergren's equation. One of the most widely used equations is Lagergren's model which is represented as:

$$
\ln \left(Q_{\mathrm{e}}-Q_{t}\right)=\ln \left(Q_{\mathrm{e}}\right)-k_{1} t
$$

Where $k_{1}$ is the rate constant of pseudo first order adsorption $\left(\mathrm{min}^{-1}\right)$ and $Q_{t}(\mathrm{mg} / \mathrm{g})$ is the dye adsorption capacity at time $t(\mathrm{~min})$.

Pseudo second order equation. The linear form of the pseudo second order model is illustrated as:

$$
\frac{t}{Q_{t}}=\frac{1}{k_{2} Q_{\mathrm{e}}^{2}}+\frac{\mathrm{t}}{Q_{\mathrm{e}}}
$$

Where $k_{2}$ is the rate constant of pseudo second order adsorption $\left(\mathrm{g}(\mathrm{mg} \mathrm{min})^{-1}\right)$.

Intra-particle diffusion model (Weber and Morris model). The possibility of intra-particle or intra-fiber diffusion during the adsorption process is investigated using the intra-particle diffusion model as:

$$
Q_{t}=k t^{1 / 2}+I
$$

Where $k\left(\mathrm{mg} \mathrm{g}^{-1} \mathrm{~min}^{-1 / 2}\right)$ is the diffusion rate constant and $I\left(\mathrm{mg} \mathrm{g}^{-1}\right)$ is a constant related to boundary layer thickness: the larger the value of $I$ is, the greater the boundary layer effect 
will be. The "bl" and "if" indices in Table 3 represent the boundary layer and intra-fiber diffusions, respectively [43].

The kinetic parameters for MB adsorption by NFAs and NFMs according to the different kinetic models are given in Table 3. The pseudo second order kinetic is more suited for modelling the MB adsorption process by the NFA or the NFM as indicated by the coefficients of determination $\left(R^{2}>0.99\right)$ and by the better agreement with the experimental equilibrium capacities of 263 and $262 \mathrm{mg} \mathrm{g}^{-1}$. The adsorption rate constant $k_{2}$ for the 3D NFA is by a factor of 4 higher than for the flat NFM.

However, the pseudo second order kinetic model cannot identify the diffusion mechanism. So, the intra-particle diffusion model was used as shown in Fig. 7 and listed in Table 3. The multi-linear plots indicate that intra-particle diffusion is involved in the adsorption process but it is not the only rate limiting step. The adsorption of MB on the NFA and NFM is a twostep process, involving a very fast adsorption on the external surface of the nanofibers $\left(k_{\mathrm{bl}}\right)$ and slow diffusion into the fibers $\left(k_{\mathrm{if}}\right)$ afterwards with a transition period in between. Comparing the kinetics of adsorption by NFA and NFM, a fast surface adsorption is observed for the aerogel in the first step due to the higher surface availability of the $3 \mathrm{D}$ structure following with almost the same amount of intra-fiber diffusion for both the flat NFM and the 3D NFA due to the same surface chemistry and equal fiber diameter.

NFA regeneration. Regeneration of adsorbents is important from the economic and environmental perspective. Reusing the NFA reduces the need for fresh adsorbent, it provides the possibility of recovering dyes, and it solves the disposal problems of used adsorbents. Easy and cost effective method are preferred among different regeneration methods like solvent washing, chemical, electrochemical, and thermal processes [44].

The desorbed percentage of dye $(D)$ was calculated using Equation 14. 


$$
D=\frac{m_{\mathrm{d}}}{m_{\mathrm{a}}} \times 100 \%
$$

Where $m_{\mathrm{d}}$ and $m_{\mathrm{a}}$ are the mass of dye desorbed and adsorbed respectively. Fig. 8A shows the effect of different $\mathrm{pH}$ on desorption efficiency and indicates that removal of dye from used NFA is possible with changing the $\mathrm{pH}$ of the solution. In other words, desorption is possible using water with the acidic $\mathrm{pH}$, while the adsorption process is preferably done under basic conditions $(\mathrm{pH}=11)$ as mentioned previously.

Fig.8B illustrates the dye adsorption efficiency of the NFA after regeneration cycles. It is clearly shown that even after 20 cycles around $80 \%$ of dye are adsorbed by the NFA, which demonstrates the reusability of the NFA. Thus it is possible to use a cost effective $\mathrm{pH}$ conditioning process to reuse the NFA. However, after 20 regeneration cycles corresponding to 90 hours of experiment in the stirred batch reactor, the NFA lost its physical integrity due to mechanical stress.

\section{Conclusions}

The field of applications for nanofibers as adsorbent material is significantly extended when switching from the flat NFM to the 3D NFA, since the NFA has a stable and tuneable hierarchical pore architecture. Surface chemistry and specific surface area of nanofibers are maintained, but the open porous structure of the NFA is favourable for the mass transport of the dye solution to the surface of the nanofibers. This is of advantage for batch operations, where adsorption velocity was enhanced by a factor of 4 when switching to the 3D NFA, but it also allowed the incorporation of the NFA into a continuously operated depth filtration process, where the pressure drop was by a factor of 40 lower than for the comparable NFM. Regenerability and promising stability of the synthesized NFAs makes them very suitable for industrial applications. 


\section{Acknowledgements}

This work was supported by Forschungsfond Aargau, TB-Safety, IVF-Hartmann AG (Thesis of F.D.), and COST ACTION MP1206 (traveling grants). 


\section{References}

[1] A.A. Adeyemo, I.O. Adeoye, O.S. Bello, Adsorption of dyes using different types of clay: a review, Appl. Water Sci., 7 (2017) 543-568.

[2] R.S. Blackburn, Natural polysaccharides and their interactions with dye molecules:

Applications in effluent treatment, Environ. Sci. Technol., 38 (2004) 4905-4909.

[3] F.M.D. Chequer, G.A.R. de Oliveira, E.R.A.c. Ferraz, J.C. Cardoso, M.V.B. Zanoni, D.P. de Oliveira, Textile Dyes: Dyeing Process and Environmental Impact, in: M. Günay (Ed.) Eco-Friendly Textile Dyeing and Finishing, InTech, Rijeka, 2013, pp. 151-176.

[4] D. Phillips, Environmentally friendly, productive and reliable: Priorities for cotton dyes and dyeing processes, J. Soc. Dyers Colour., 112 (1996) 183-186.

[5] Y. Zhang, H. Ou, H. Liu, Y. Ke, W. Zhang, G. Liao, D. Wang, Polyimide-based carbon nanofibers: A versatile adsorbent for highly efficient removals of chlorophenols, dyes and antibiotics, Colloids Surf., A, 537 (2018) 92-101.

[6] M.T. Yagub, T.K. Sen, S. Afroze, H.M. Ang, Dye and its removal from aqueous solution by adsorption: A review, Adv. Colloid Interface Sci., 209 (2014) 172-184.

[7] K.K.H. Choy, G. McKay, J.F. Porter, Sorption of acid dyes from effluents using activated carbon, Resour. Conserv. Recy., 27 (1999) 57-71.

[8] P. Hadi, J.X. Guo, J. Barford, G. Mckay, Multilayer Dye Adsorption in Activated Carbons-Facile Approach to Exploit Vacant Sites and Interlayer Charge Interaction, Environ. Sci. Technol., 50 (2016) 5041-5049.

[9] M. Aliabadi, K. Morshedzadeh, H. Soheyli, Removal of hexavalent chromium from aqueous solution by lignocellulosic solid wastes, Int. J. Environ. Sci. Technol., 3 (2006) 321325.

[10] M. Aliabadi, S. Moussavi, S. Nayebi-Far, M. Asri, Detoxification of chromium(VI) contaminated water using natural adsorbents, Int. J. Biosci., 2 (2012) 89-94. 
[11] M.A.M. Salleh, D.K. Mahmoud, W.A.W.A. Karim, A. Idris, Cationic and anionic dye adsorption by agricultural solid wastes: A comprehensive review, Desalination, 280 (2011) 113.

[12] A.K. Jain, V.K. Gupta, S. Jain, Suhas, Removal of chlorophenols using industrial wastes, Environ. Sci. Technol., 38 (2004) 1195-1200.

[13] S.D. Lambert, N.J.D. Graham, C.J. Sollars, G.D. Fowler, Evaluation of inorganic adsorbents for the removal of problematic textile dyes and pesticides, Water Sci. Technol., 36 (1997) 173-180.

[14] S. Xiao, H. Ma, M. Shen, S. Wang, Q. Huang, X. Shi, Excellent copper(II) removal using zero-valent iron nanoparticle-immobilized hybrid electrospun polymer nanofibrous mats, Colloids Surf., A, 381 (2011) 48-54.

[15] M.S. Islam, M.S. Rahaman, J.H. Yeum, Phosphine-functionalized electrospun poly(vinyl alcohol)/silica nanofibers as highly effective adsorbent for removal of aqueous manganese and nickel ions, Colloids Surf., A, 484 (2015) 9-18.

[16] Z. Li, T. Li, L. An, H. Liu, L. Gu, Z. Zhang, Preparation of chitosan/polycaprolactam nanofibrous filter paper and its greatly enhanced chromium(VI) adsorption, Colloids Surf., A, 494 (2016) 65-73.

[17] A.M. Bazargan, M. Keyanpour-rad, F.A. Hesari, M.E. Ganji, A study on the microfiltration behavior of self-supporting electrospun nanofibrous membrane in water using an optical particle counter, Desalination, 265 (2011) 148-152.

[18] N.M. Mahmoodi, Z. Mokhtari-Shourijeh, Preparation of PVA-chitosan Blend Nanofiber and Its Dye Removal Ability from Colored Wastewater, Fiber. Polym., 16 (2015) 1861-1869. [19] M.M. Teng, F.T. Li, B.R. Zhang, A.A. Taha, Electrospun cyclodextrin-functionalized mesoporous polyvinyl alcohol/SiO2 nanofiber membranes as a highly efficient adsorbent for indigo carmine dye, Colloids Surf., A, 385 (2011) 229-234. 
[20] K. Yoon, B.S. Hsiao, B. Chu, Formation of functional polyethersulfone electrospun membrane for water purification by mixed solvent and oxidation processes, Polymer, 50 (2009) 2893-2899.

[21] Y. Si, J.Y. Yu, X.M. Tang, J.L. Ge, B. Ding, Ultralight nanofibre-assembled cellular aerogels with superelasticity and multifunctionality, Nat. Commun., 5 (2014).

[22] S.H. Jiang, G.G. Duan, U. Kuhn, M. Morl, V. Altstaedt, A.L. Yarin, A. Greiner, Spongy Gels by a Top-Down Approach from Polymer Fibrous Sponges, Angew. Chem. Int. Ed., 56 (2017) 3285-3288.

[23] F. Deuber, C. Adlhart, From Short Electrospun Nanofibers to Ultralight Aerogels with Tunable Pore Structure, Chimia, 71 (2017) 236-240.

[24] F. Deuber, S. Mousavi, M. Hofer, C. Adlhart, Tailoring Pore Structure of Ultralight Electrospun Sponges by Solid Templating, ChemistrySelect, 1 (2016) 5595-5598.

[25] M. Aliabadi, M. Irani, J. Ismaeili, H. Piri, M.J. Parnian, Electrospun nanofiber membrane of PEO/Chitosan for the adsorption of nickel, cadmium, lead and copper ions from aqueous solution, Chem. Eng. J., 220 (2013) 237-243.

[26] X. Wang, B. Ding, G. Sun, M. Wang, J. Yu, Electro-spinning/netting: A strategy for the fabrication of three-dimensional polymer nano-fiber/nets, Prog. Mater Sci., 58 (2013) 11731243.

[27] X. Wang, J. Ge, Y. Si, B. Ding, Adsorbents Based on Electrospun Nanofibers, in: B. Ding, J. Yu (Eds.) Electrospun Nanofibers for Energy and Environmental Applications, Springer Berlin Heidelberg, Berlin, Heidelberg, 2014, pp. 473-495.

[28] G.H. Jing, L. Wang, H.J. Yu, W.A. Amer, L. Zhang, Recent progress on study of hybrid hydrogels for water treatment, Colloids Surf., A, 416 (2013) 86-94.

[29] M. Chau, K.J. De France, B. Kopera, V.R. Machado, S. Rosenfeldt, L. Reyes, K.J.W. Chan, S. Forster, E.D. Cranston, T. Hoare, E. Kumacheva, Composite Hydrogels with 
Tunable Anisotropic Morphologies and Mechanical Properties, Chem. Mater., 28 (2016) $3406-3415$.

[30] S. Deville, Freeze-casting of porous ceramics: A review of current achievements and issues, Adv. Eng. Mater., 10 (2008) 155-169.

[31] J.Q. Zhao, X.F. Zhang, X. He, M.J. Xiao, W. Zhang, C.H. Lu, A super biosorbent from dendrimer poly(amidoamine)-grafted cellulose nanofibril aerogels for effective removal of Cr(VI), J. Mater. Chem. A, 3 (2015) 14703-14711.

[32] F. Deuber, S. Mousavi, L. Federer, C. Adlhart, Amphiphilic Nanofiber-Based Aerogels for Selective Liquid Absorption from Electrospun Biopolymers, Adv. Mater. Interfaces., 4 (2017).

[33] P.R. Ginimuge, S.D. Jyothi, Methylene Blue: Revisited, J. Anaesthesiol., Clin. Pharmacol., 26 (2010) 517-520.

[34] T.K. Sen, S. Afroze, H.M. Ang, Equilibrium, Kinetics and Mechanism of Removal of Methylene Blue from Aqueous Solution by Adsorption onto Pine Cone Biomass of Pinus radiata, Water Air Soil Poll., 218 (2011) 499-515.

[35] G. Crini, P.M. Badot, Application of chitosan, a natural aminopolysaccharide, for dye removal from aqueous solutions by adsorption processes using batch studies: A review of recent literature, Prog. Polym. Sci., 33 (2008) 399-447.

[36] Q.X. Fu, X.Q. Wang, Y. Si, L.F. Liu, J.Y. Yu, B. Ding, Scalable Fabrication of Electrospun Nanofibrous Membranes Functionalized with Citric Acid for High-Performance Protein Adsorption, ACS Appl. Mater. Interfaces, 8 (2016) 11819-11829.

[37] S.J. Angyal, Complexes of Sugars with Cations, in: H.S. Isabell (Ed.) Carbohydrates in Solution, American Chemical Society, Washington D.C., 1973, pp. 106-120.

[38] A.A. Atshan, Adsorption of Methyl Green Dye onto Bamboo in Batch and Continuous System, Iraqi J. Chem.Pet. Eng., 15 (2014) 65- 72. 
[39] I. Langmuir, The Constitution and Fundamental Properties of Solids and Liquids. II. Liquids, J. Am. Chem. Soc., 39 (1917) 1848-1906.

[40] B. Abbad, A. Lounis, Removal of methylene blue from colored effluents by adsorption onto ZnAPSO-34 nanoporous material, Desalin. Water. Treat., 52 (2014) 7766-7775. [41] G. Mezohegyi, F.P. van der Zee, J. Font, A. Fortuny, A. Fabregat, Towards advanced aqueous dye removal processes: A short review on the versatile role of activated carbon, $\mathrm{J}$. Environ. Manage., 102 (2012) 148-164.

[42] N. Kannan, M.M. Sundaram, Kinetics and mechanism of removal of methylene blue by adsorption on various carbons - a comparative study, Dyes Pigments, 51 (2001) 25-40. [43] V. Fierro, V. Torne-Fernandez, D. Montane, A. Celzard, Adsorption of phenol onto activated carbons having different textural and surface properties, Microporous Mesoporous Mater., 111 (2008) 276-284.

[44] S. Kulkarni, J. Kaware, Regeneration and Recovery in Adsorption, Int. J. Innovative Sci., Eng. Tech., 1 (2014) 61-64. 
Table 1. Thermodynamic parameters ${ }^{\text {a }}$

\begin{tabular}{|cccccc|}
\hline$\gamma_{0}$ & $\Delta H^{0}$ & $\Delta S^{0}$ & \multicolumn{3}{c|}{$\Delta G^{0}\left(\mathrm{~kJ} \mathrm{~mol}^{-1}\right)$} \\
\cline { 4 - 6 }$(\mathrm{ppm})$ & $\left(\mathrm{kJ} \mathrm{mol}^{-1}\right)$ & $\left(\mathrm{kJ} \mathrm{mol}^{-1} \mathrm{~K}^{-1}\right)$ & $25^{0} \mathrm{C}$ & $35^{0} \mathrm{C}$ & $50^{0} \mathrm{C}$ \\
\hline 100 & 13.980 & 0.1297 & -24.6 & -25.9 & -27.9 \\
\hline
\end{tabular}

${ }^{a}$ Conditions: $V(\mathrm{MB}$ solution $)=150 \mathrm{ml}, \gamma_{0}(\mathrm{MB})=100 \mathrm{ppm}, m($ adsorbent $)=100 \mathrm{mg}, t=3$ hours. 
Table 2. Equilibrium isotherm models according to Langmuir, with calculated and experimental maximum amount of dye covering the monolayer, $Q_{\max , \text { calc. }}$ and $Q_{\max , \text { exp. }}$ Langmuir constant, $k_{a}$, separation factor, $R_{\mathrm{L}}$, Freundlich, with Freundlich constant, $K_{\mathrm{F}}$, and indicator $n$.

\begin{tabular}{|c|c|c|}
\hline Isotherm & Parameter & Quantity \\
\hline \multirow{5}{*}{ Langmuir } & $Q_{\text {max,exp. }}\left(\mathrm{mg} \mathrm{g}_{\text {aerogel }}^{-1}\right)$ & 383 \\
\hline & $Q_{\text {max,calc. }}\left(\mathrm{mg} \mathrm{g}_{\text {aerogel }}^{-1}\right)$ & 370 \\
\hline & $K_{\mathrm{L}}\left(\mathrm{l} \mathrm{mg}^{-1}\right)$ & 0.42 \\
\hline & $R_{\mathrm{L}}$ & 0.0018 \\
\hline & $R^{2}$ & 0.99 \\
\hline \multirow{3}{*}{ Freundlich } & $K_{\mathrm{F}}\left(\lg _{\text {aerogel }}^{-1}\right)$ & 89.3 \\
\hline & $n$ & 4.32 \\
\hline & $R^{2}$ & 0.67 \\
\hline
\end{tabular}


Table 3. Kinetic parameters for $\mathrm{MB}$ adsorption according to pseudo first order, pseudo second order, and intra particle diffusion model for the 3D NFA and the flat NFM.

\begin{tabular}{|c|c|c|c|}
\hline \multirow{2}{*}{ Model } & \multirow{2}{*}{ Parameter } & \multicolumn{2}{|c|}{ Quantity } \\
\hline & & NFA & NFM \\
\hline \multirow{2}{*}{$\begin{array}{c}\text { Mass } \\
\text { concentration } \\
\text { Experimental } \\
\text { equilibrium } \\
\text { capacity }\end{array}$} & $\gamma_{0}(\mathrm{ppm})$ & 200 & 200 \\
\hline & $Q_{\mathrm{e}, \exp }\left(\mathrm{mg} \mathrm{g}^{-1}\right)$ & 263 & 262 \\
\hline \multirow{3}{*}{$\begin{array}{l}\text { Pseudo first } \\
\text { order }\end{array}$} & $Q_{\mathrm{e}, 1 \mathrm{st}}\left(\mathrm{mg} \mathrm{g}^{-1}\right)$ & 155 & 223 \\
\hline & $k_{1} \times 10^{-4}\left(\mathrm{~min}^{-1}\right)$ & 212 & 167 \\
\hline & $R_{1 \mathrm{st}}^{2}$ & 0.96 & 0.99 \\
\hline \multirow{3}{*}{$\begin{array}{l}\text { Pseudo second } \\
\text { order }\end{array}$} & $Q_{\mathrm{e}, 2 \mathrm{nd}}\left(\mathrm{mg} \mathrm{g}^{-1}\right)$ & 270 & 294 \\
\hline & $k_{2} \times 10^{-4}\left(\mathrm{~g} \mathrm{mg}^{-1} \mathrm{~min}^{-1}\right)$ & 4.37 & 1.14 \\
\hline & $R_{2 \mathrm{nd}}^{2}$ & 0.99 & 0.99 \\
\hline \multirow{4}{*}{$\begin{array}{l}\text { Intra-particle } \\
\text { diffusion }\end{array}$} & $k_{\mathrm{bl}}\left(\mathrm{mg} \mathrm{g}^{-1} \min ^{-\frac{1}{2}}\right)$ & 50.6 & 24.8 \\
\hline & $k_{\mathrm{if}}\left(\mathrm{mg} \mathrm{g}^{-1} \min ^{-\frac{1}{2}}\right)$ & 4.84 & 4.49 \\
\hline & $I\left(\mathrm{mg} \mathrm{g}^{-1}\right)$ & 195 & 194 \\
\hline & $R^{2}$ & 0.97 & 0.91 \\
\hline
\end{tabular}




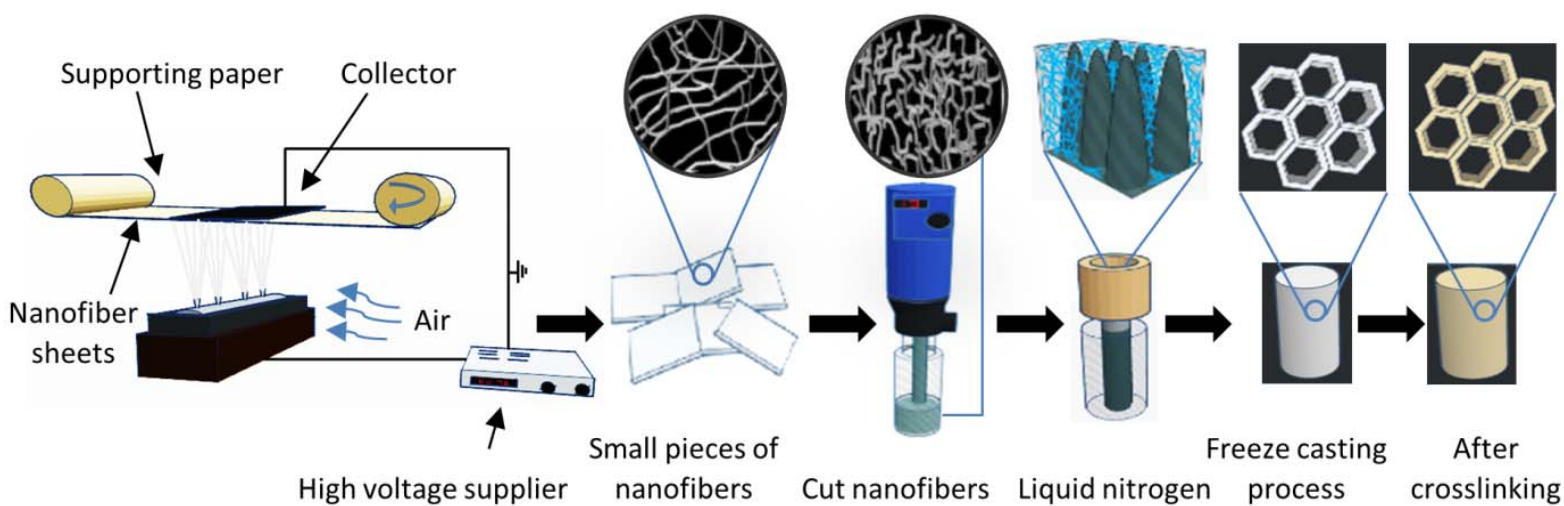

Fig. 1. Schematic illustration of nanofiber aerogel synthesis 
(A)

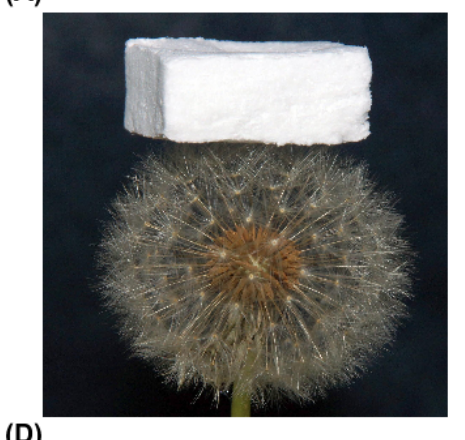

(D)

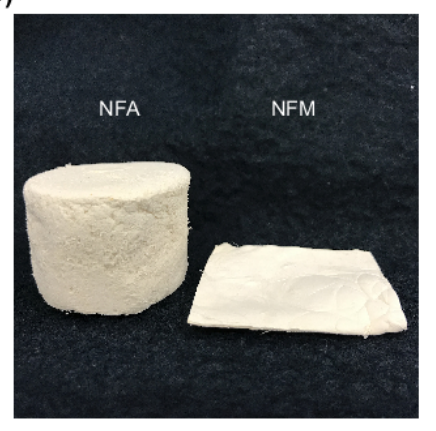

(B)

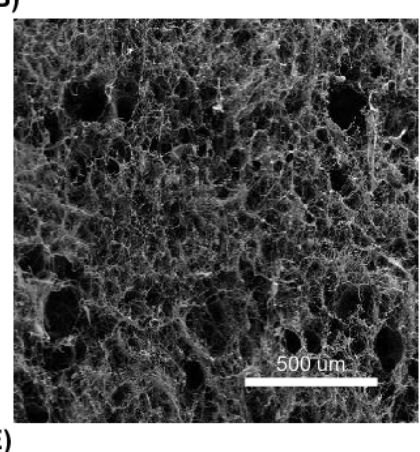

(E)

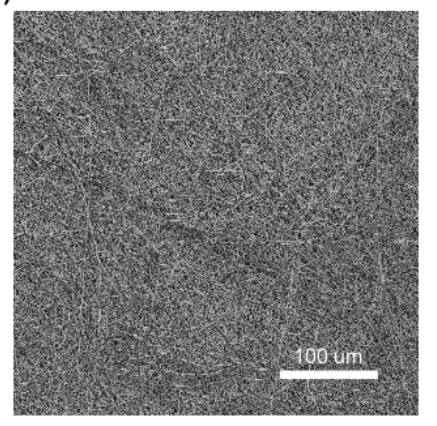

(C)

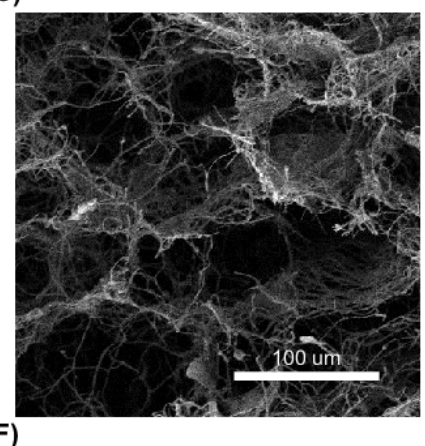

(F)

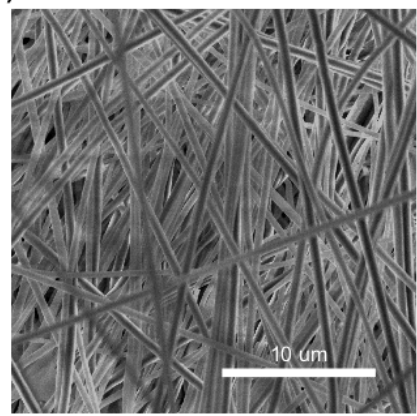

Fig. 2. Morphology and structure of the nanofiber aerogel (NFA) and membrane (NFM). (A)

Ultralight NFA on a dandelion, (B) and (C) SEM images of NFA cross sections illustrating the pore architecture, (D) crosslinked 3D NFA and 2D NFM with equivalent mass, (E) and (F) SEM images of NFM contrasting the pore architecture of NFAs. 
(A)

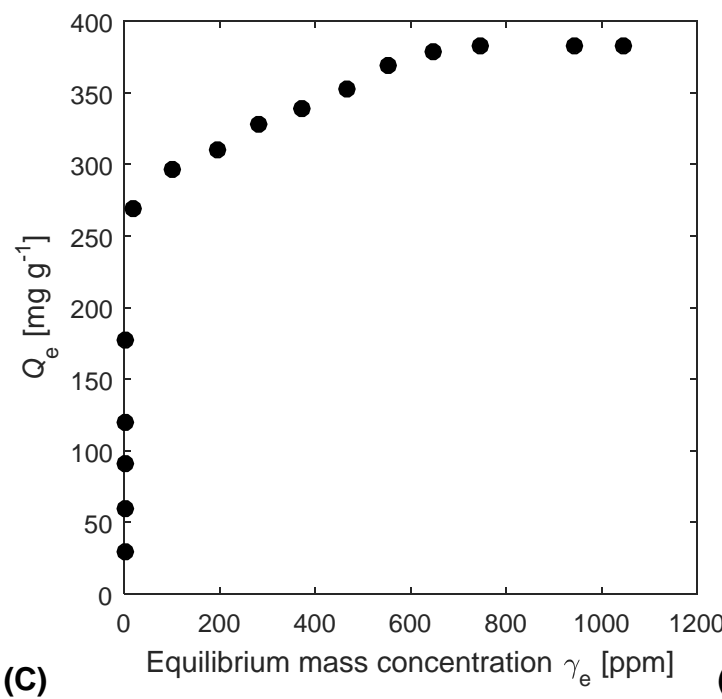

(C)

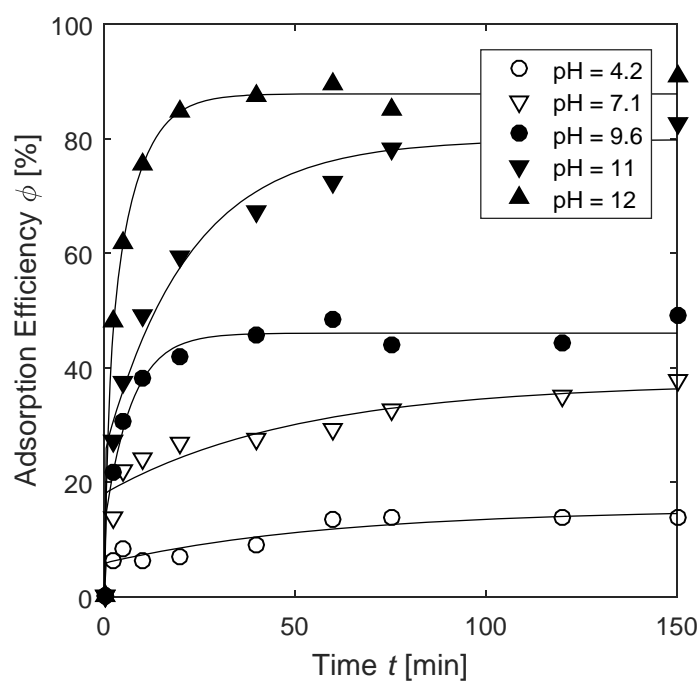

(B)

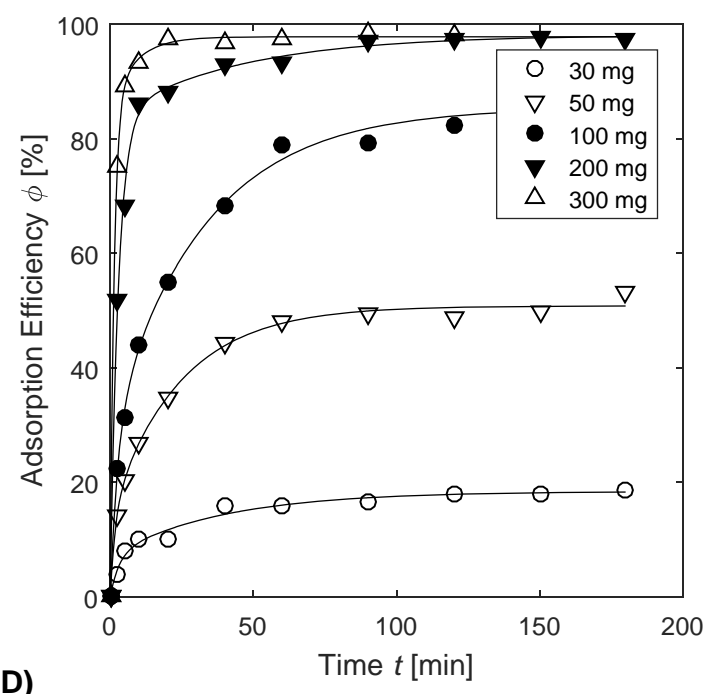

(D)

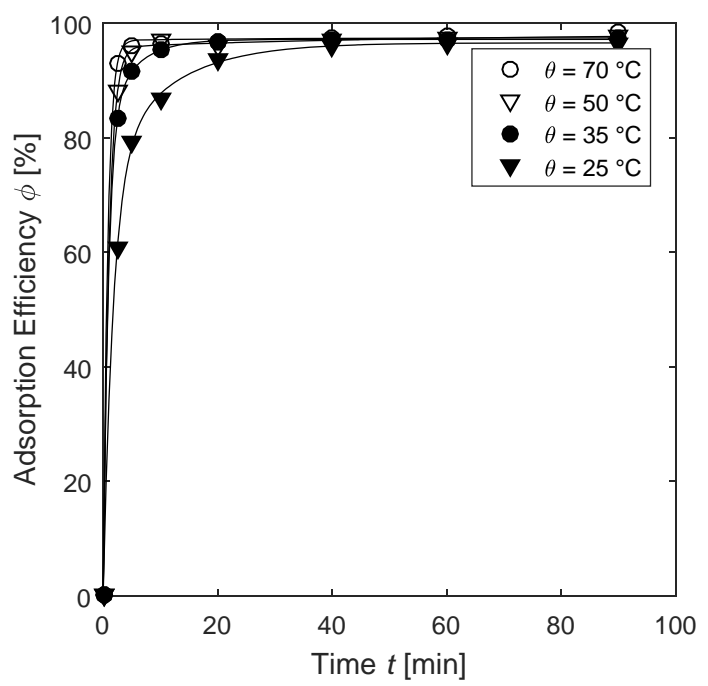

Fig. 3. (A) Effect of concentration on adsorbent equilibrium capacity $Q_{\mathrm{e}}$, (B) effect of adsorbent amount, (C) $\mathrm{pH}$, and (D) temperature on adsorption efficiency. Conditions: $150 \mathrm{ml}$ dye solution, $\gamma_{0}=$ $200 \mathrm{ppm}, m(\mathrm{NFA})=200 \mathrm{mg}, \mathrm{pH}=11, T=25{ }^{\circ} \mathrm{C}$ with one condition changing in each experiment. 
(A)

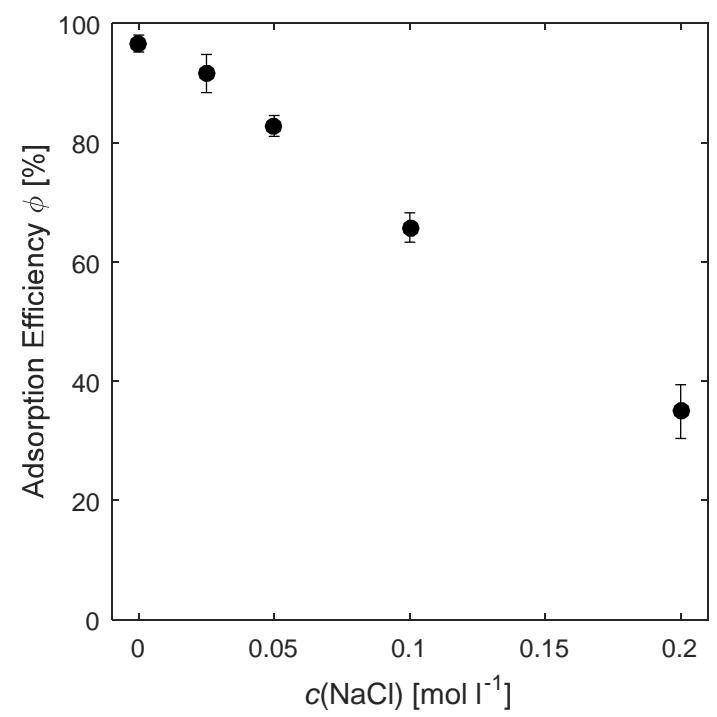

(B)

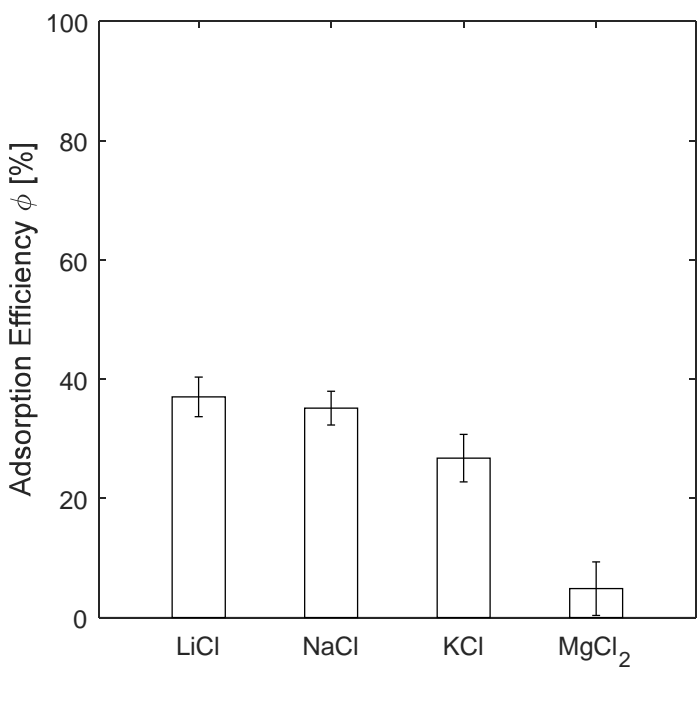

Fig. 4. Effect of ion strength (A) and ion radius and charge (B) on the adsorption efficiency of the nanofiber aerogel, $\gamma_{0}=200 \mathrm{ppm}$. 
(A)

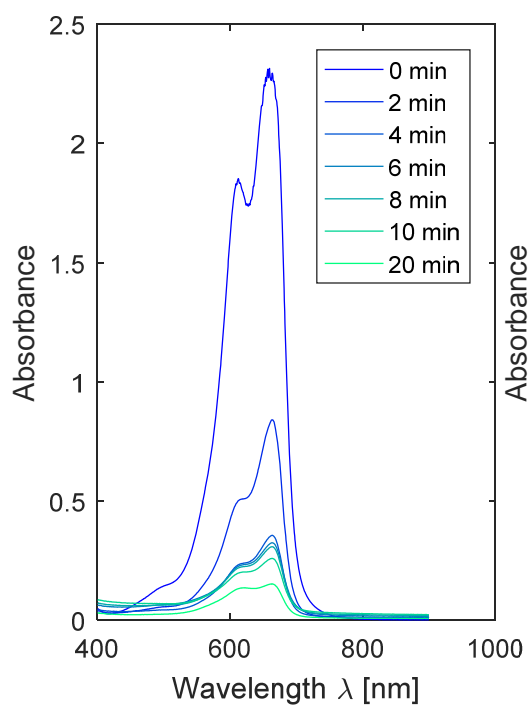

(B)

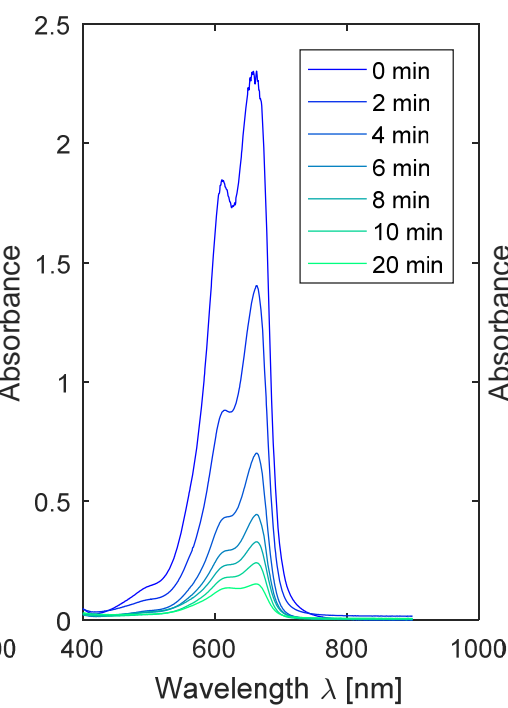

(C)

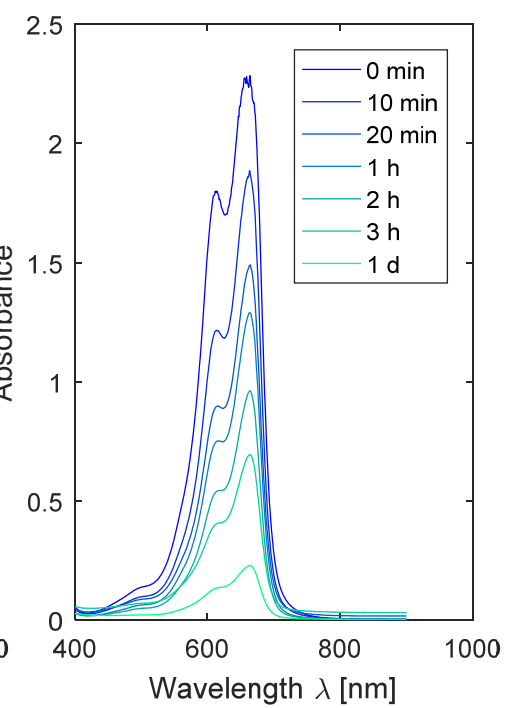

Fig. 5. UV spectra showing the effect of external mechanical forces on the adsorption of a $\gamma_{0}=100$ ppm dye solution: (a) with compression and release cycles $(\sim 60 \%)$ on the nanofiber aerogel every 20 seconds, (b) stirring the solution with $300 \mathrm{rpm}$ and (c) without stirring and compression cycles. 
(A)

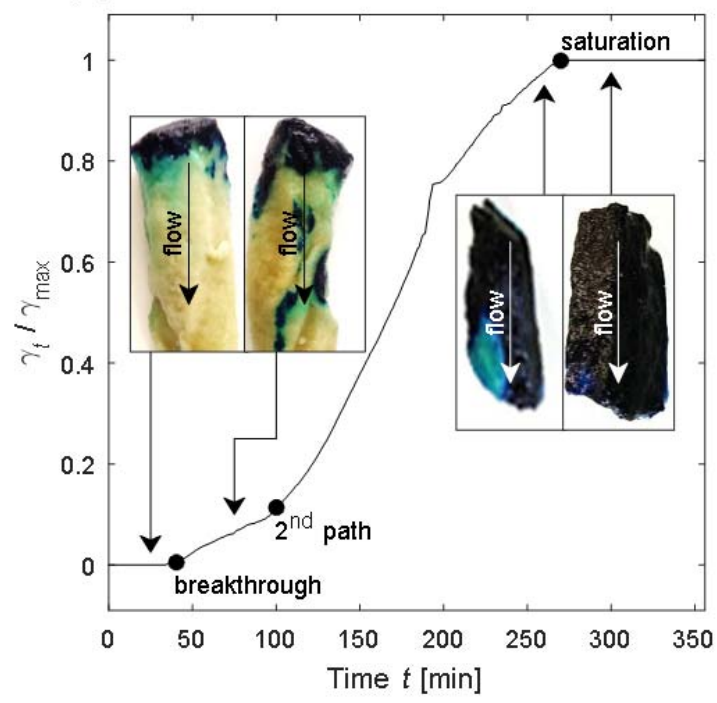

(B)

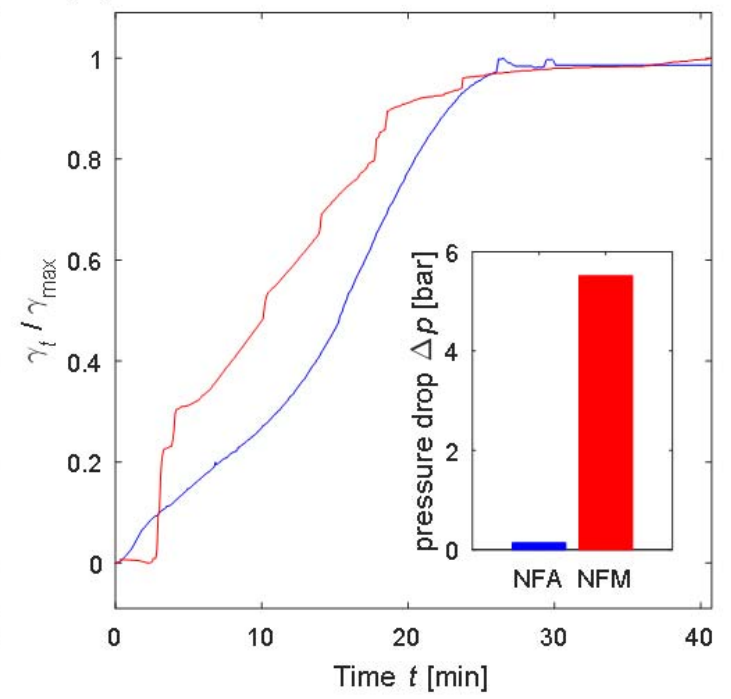

Fig. 6. Continuous adsorption of MB with (A) $100 \mathrm{~mm}$ NFA filter column and (B) $40 \mathrm{~mm}$ NFA filter column (blue) and equivalent mass of nanofiber membrane, NFM, red, with an increased pressure drop by a factor of 40 from 0.14 bar to $5.5 \operatorname{bar}\left(\gamma_{0}=25 \mathrm{ppm}\right.$, flowrate $\left.=4.5 \mathrm{ml} \mathrm{min}^{-1}, \mathrm{pH}=11\right)$. The insets in (A) are photographs of representative NFAs at the respective part of the experiment. 


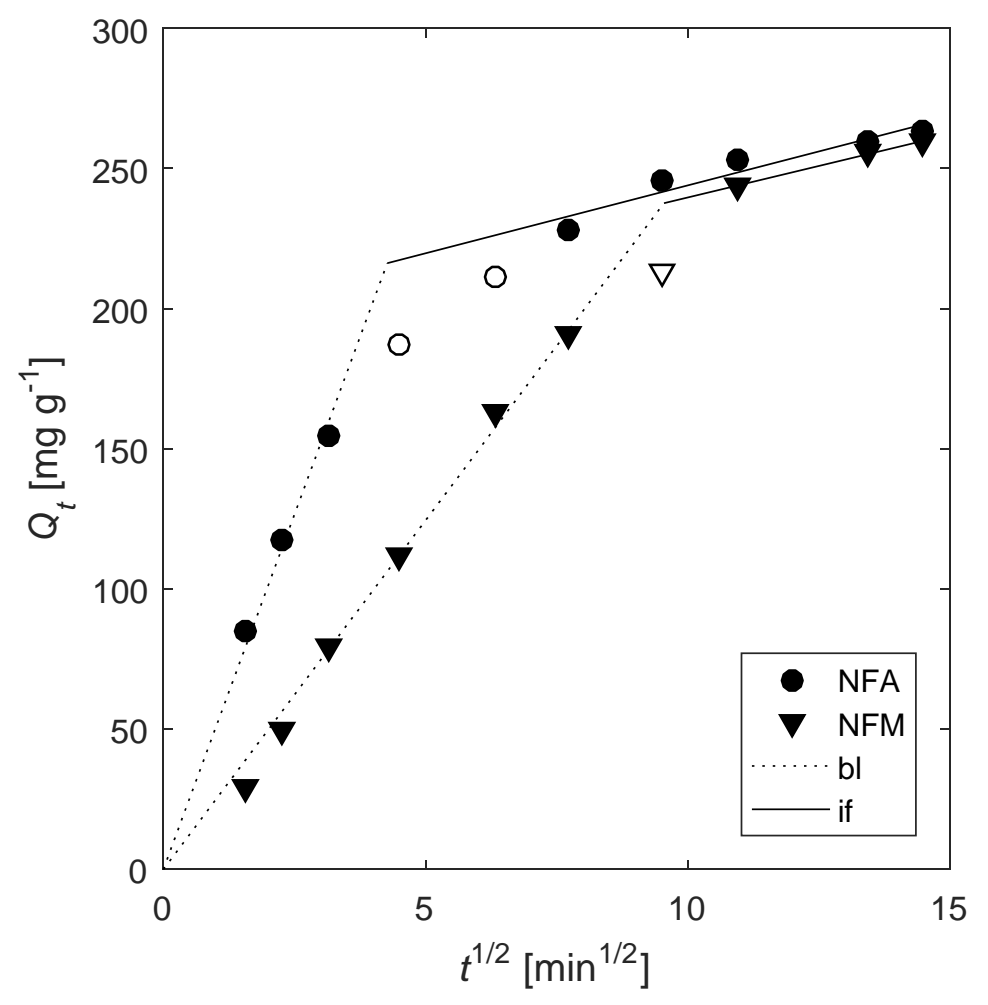

Fig. 7. Dye adsorption kinetics according to the intra-particle diffusion model for the nanofiber aerogel (NFA) and the nanofiber membrane (NFM) with boundary layer (bl) and intra-fiber (if) adsorption regimes; $m$ (adsorbent $)=100 \mathrm{mg}$, stirring speed $=500 \mathrm{rpm}, \mathrm{pH}=11$. Values with empty marks were excluded from the fits. 
(A)

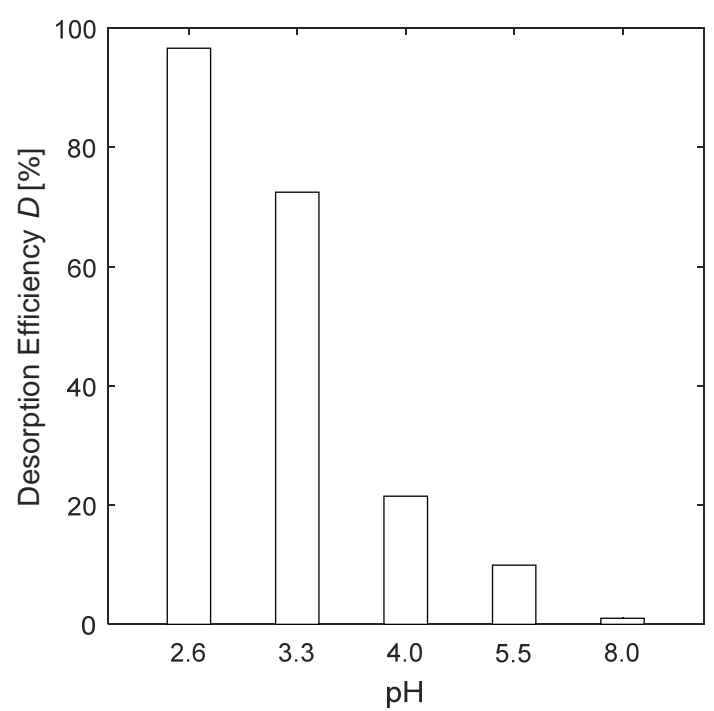

(B)

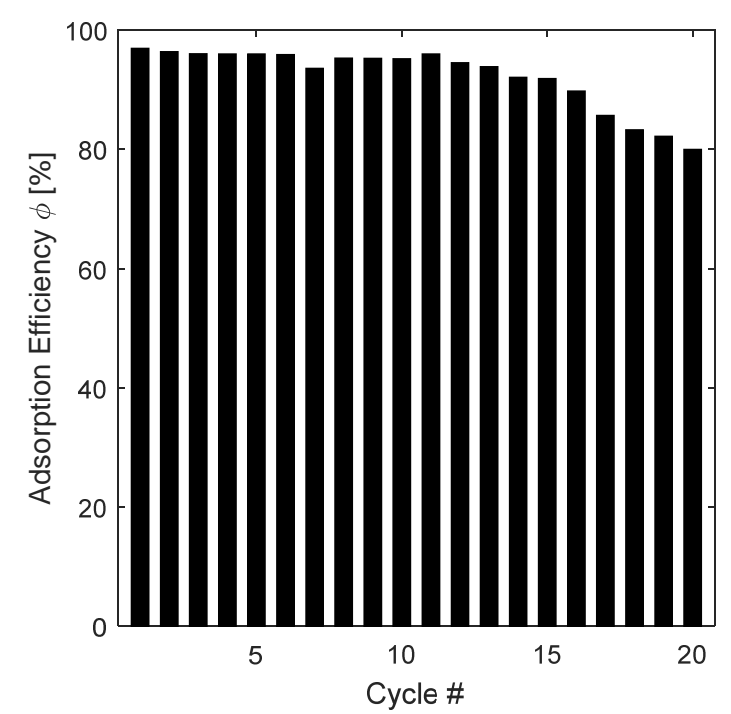

Fig. 8. (A) effect of $\mathrm{pH}$ on desorption efficiency of $200 \mathrm{mg}$ of NFA in $200 \mathrm{ppm}$ concentrated dye solution and (B) adsorption / desorption cycles for a $200 \mathrm{mg}$ piece of NFA using $\mathrm{pH}=11$ in the adsorption and $\mathrm{pH}=3$ in the desorption. 